Bouille de Vicente, Luis.

Investigador artístico. Profesor asociado en Universidad Castilla-La Mancha (UCLM), departamento de Didáctica de la expresión corporal, plástica y musical. Doctorando en el programa de la UCLM Investigación en Humanidades, Artes y Educación.

\title{
Cine Sólido, la indiscernibilidad de lo actual y lo virtual en nuestra experiencia del espacio cotidiano y sus objetos como escritura.
}

\author{
TIPO DE TRABAJO
}

Comunicación.

PALABRAS CLAVE

Instalación artística, paracinema, imagen dialéctica, imagen-tiempo, escritura espacial.

KEY WORDS

Artistic installation, paracinema, dialectical image, time-image, spatial writing.

\section{RESUMEN}

La práctica artística de investigación propuesta con la denominación de Cine Sólido indaga en las relaciones narrativas del espacio, tanto individuales como sociales, que se establecen entre el lenguaje, en este caso cinematográfico, y los objetos cotidianos que componen ese espacio; dicho de otro modo, constituye un caso particular de escritura espacial.

Partiendo de un guion cinematográfico ya escrito, y utilizando como herramientas conceptuales y creativas las teorías del montaje de S. Eisenstein, se "traducen" los enunciados descriptivos de las diferentes secuencias cinematográficas propuestas en el guion mediante el uso simbólico de series de objetos domésticos y cotidianos dispuestos directamente sobre el suelo, a modo de naturaleza muerta o vanitas. De la proposición eisensteniana del montaje como ideograma, "agua + ojo = «llorar»" (relación dialéctica entre imágenes cinematográficas), pasamos a otro tipo de relación dialéctica, no ya entre imágenes sino directamente entre objetos "sólidos".

Producto de este dispositivo de extrañamiento del espacio cotidiano se manifiesta lo que en su estudio sobre el cine Gilles Deleuze llama una imagen-cristal, una variedad de imagen-tiempo, en la que las potencias de lo posible, de la infinidad de imágenes virtuales que estas combinaciones de objetos conjugan en sus relaciones simbólicas, se funden con la imagen actual perceptiva que de los objetos obtenemos, estableciéndose un circuito de intercambios en el pensamiento, que nos induce a una actividad contemplativa de una "situación óptica pura".

Esta actividad intensa de pensamiento sobre nuestra realidad cotidiana se caracteriza por ejercitar una lectura del espacio tal y como Walter Benjamin propone al rastrear las características de la modernidad en las calles y pasajes de la ciudad de París de principios del siglo xx. Cine Sólido es un modo de rastrear en el tiempo actual las "mediaciones espaciales" (Olafur Eliasson) a las que nos enfrentamos y que predisponen nuestro comportamiento. 


\section{ABSTRACT}

The artistic-research-based practice proposed with the designation Cine Sólido [Solid Cinema] inquires in the narrative relations of space, both individuals than socials, that are stablished between the language, cinematographic in this case, and the everyday objects that composes these space; in other words, constitute a particular case of spatial writing.

Based on a film script already written, and using like conceptual and creative tools the montage theories of S. Eisenstein, will "translate" the descriptive statements of the different film sequences proposed in the script through everyday objects series' symbolic use directly disposed on the floor, as a still life or vanitas. From eisenstenian proposition of montage as ideogram, "water + eye = "to cry»" (dialectical relation between cinematographic images), go through to another dialectical relation, not already between images but between "solid" objects directly.

Product of this everyday space's estrangement device will display that Gilles Deleuze's film studies named a crystal-image, a time-image's variation, where the possible potencies, the myriad of virtual images that this objects combinations marry up in its symbolic relations, will merge with the current perceptual image of the objects we get, establishing an exchanges circuit in thought, which leads us to a contemplative activity of a "pure optical situation".

This intense activity of thinking about our daily reality is characterized by a reading space exercise as Walter Benjamin proposes to trace the characteristics of modernity in early twentieth century city of Paris' passages and streets. Cine Sólido is a way to track in the current time the "spatial mediations" (Olafur Eliasson) to which we face and predispose our behavior.

\section{CONTENIDO}

\section{LA MUESTRA}

Si nos atenemos a la presentación de su resultado final, Cine Sólido es una instalación artística formada por agrupaciones ordenadas, o series, de objetos heteróclitos del ámbito doméstico o cotidiano [ilustración 1]; la elección de los artefactos y su combinación corresponden a una labor de "traducción": a partir de un guion cinematográfico previamente escrito o elegido para la ocasión [ilustración 2], se extraen de cada una de las secuencias descritas un enunciado significativo o lexía ${ }^{1}$, el cual es traducido a combinaciones de objetos cuya interpretación, tanto formal como simbólica, pueden suplantar a las significaciones de las palabras escritas en el enunciado.

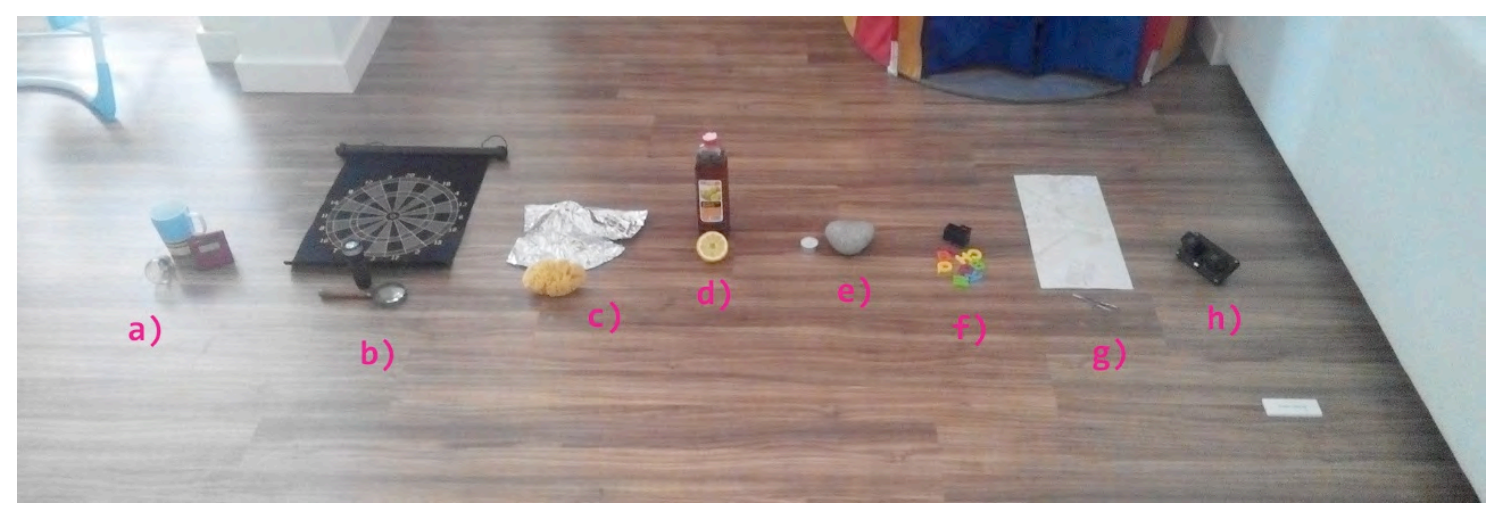

Ilustración 1. Instalación. (Secuencia 1: DORMITORIO APARTAMENTO. INTERIOR / DÍA.)

\footnotetext{
${ }^{1}$ Barthes, Roland: S/Z, Siglo Veintiuno, Madrid, 1980, pp. 8-12.
} 


\section{DORMITORIO APARTAMENTO, INTERIOR / DIA}

ANA (Mujer de 37 anos, morena, alta, de porte tranquilo y estable) se despierta en su dormitorio. Lentamente se despereza y se levanta. ANA se dirige hacia la ventana y mira a través de ella. El sol se asoma por entre las boscosas montahias.

ANA :

(Gesto de disqusto)

- ¡Joder! Otra vez 10 mismo. Estoy harta. ¡Mira

dónde está la catedral! ¡No me 10 puedo creer!

ANa se acerca a la mesa $y$ se pone a teclear en el ordenador. AI cabo de unos segundos la impresora comienza a funcionar y expulsa un papel. ANA lo coge y lo mira con resignación.

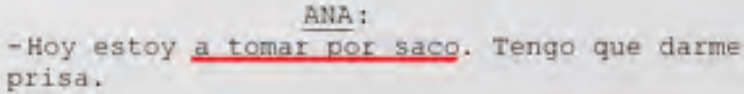

ANA sale de la habitación.

\section{llustración 2. Guion. (Secuencia 1: DORMITORIO APARTAMENTO. INTERIOR / DÍA.)}

\section{EL PROCESO.}

En cuanto al proceso de trabajo, los métodos lingüísticos predominan sobre el resto, incluidos los formales o estéticos: se procede en primer lugar mediante una lectura analítica del guion cinematográfico destacando las partes más importantes y suprimiendo lo accesorio, para posteriormente sintetizar los acontecimientos más relevantes de cada secuencia en su correspondiente lexía o unidad de lectura que contiene todas las capas de sentido incluidas en el texto ("significante tutor") [ilustración 3], según Barthes. Puede parecer que esta forma de actuar sobre el texto es destructiva con él, pero al entender de Nelson Goodman, es así como se "crean mundos" ${ }^{2}$ nuevos.

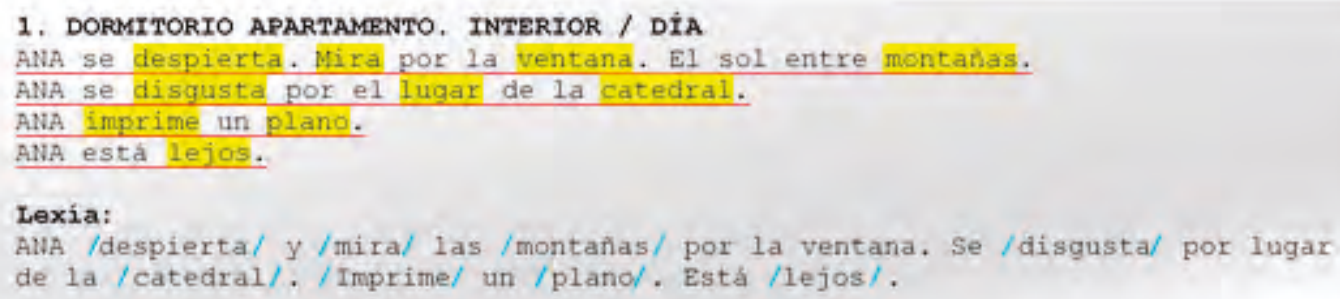

\section{Ilustración 3. Lexía. (Secuencia 1: DORMITORIO APARTAMENTO. INTERIOR / DÍA.)}

A partir de las lexías-secuencias comienza el trabajo de "traducción" de palabras a objetos, a través de la multiplicidad de asociaciones que se pueden establecer atendiendo a tres niveles de análisis ${ }^{3}$ : el nivel "literal" de su definición en el diccionario, el nivel "metafórico" de su interpretación cultural e histórica por parte de la enciclopedia, y el nivel "pragmático" basado en los usos personales o idiolecto que cada persona experimenta en relación a uno u otro objeto. Así, cada palabra de la lexía es "representada" por un objeto o una serie de éstos basándose en las asociaciones que se pueden extraer de su estudio y análisis [ilustración 4].

\footnotetext{
${ }^{2}$ Goodman, Nelson: Maneras de hacer mundos, Visor, Madrid, 1990.

a) Composición y descomposición, b) ponderación, c) ordenación, d) supresión y complementación y e) deformación.

${ }^{3}$ Reelaboración de las tesis presentadas por Umberto Eco en relación a las maneras de lectura de un texto, en Eco, Umberto: Lector in fábula, Lumen, Barcelona, 1993
} 




\section{Ilustración 4. Objetos. (Secuencia 1: DORMITORIO APARTAMENTO. INTERIOR / DÍA.)}

Por último, la forma de presentación y colocación de los objetos siempre se realiza sobre una superficie horizontal, ya sea una mesa o, preferentemente, el suelo, separando por medio de intervalos regulares las series de objetos que forman parte del conjunto global o secuencia; cabe destacar que la combinación de enseres nunca procede por construcción o superposición de unos sobre otros, sino únicamente por yuxtaposición, de ponerlos unos al lado de otros, y que la "construcción" se lleve a cabo en la mente de los espectadores-lectores que tratan de descifrar el enigma que se les presenta; el conjunto de objetos va acompañado por una cartela con la lexía o texto descriptivo de la secuencia, que actuaría como "pie de foto" que da la pista de sus posibles interpretaciones, un jeroglífico tridimensional dispuesto para ser leído en un acto de adivinación.

En este proceso de trabajo brevemente descrito surgen una serie de conceptos que refuerzan la idea artística, literaria, cinematográfica y espacial que la denominación Cine Sólido anticipa, y que se comprometen con uno de los efectos más relevantes de la instalación: hacer de la experiencia de un estado de cosas actual una lectura virtual del espacio cotidiano, con todo lo que ello implica de intensificación de la experiencia y conocimiento. A continuación analizamos someramente algunos de estos conceptos más importantes:

\section{MONTAJE}

A la combinación de objetos yuxtapuestos para la elaboración de cada una de las secuencias integrantes de Cine Sólido también se le puede denominar montaje. Precisamente este término resulta clave para comprender las prácticas artísticas de las vanguardias históricas, según Peter Bürger, que, en su Teoría de la Vanguardia, establece una clasificación de la obra de arte atendiendo a su carácter orgánico o inorgánico: la obra orgánica (simbólica) sería aquella en la que se oculta el artificio, su construcción, dando aparente sensación de unidad de las partes para formar el todo, mientras que la obra inorgánica (alegórica) muestra abiertamente su forma de construcción, evitando la sensación de completitud de la obra ${ }^{4}$. Son precisamente las obras vanguardistas las calificadas como inorgánicas, las que dejan ver la mano del artista en su construcción, evidenciando su carácter convencional y arbitrario frente a las obras de arte clásico, que parecen fruto de la propia naturaleza. Entre los procedimientos de construcción alegóricos destaca el del montaje; para Bürger, el procedimiento que ilustraría la obra de vanguardia sería el montaje puesto en juego en los collages cubistas; en éstos, fragmentos de realidad seleccionados por el artista se combinan en la unidad del cuadro, del espacio de representación, con elementos pictóricos realizados por el artista: las obras vanguardistas "no remiten como signo a la realidad, sino que son realidad" 5 .

Pero también el montaje propiamente cinematográfico resulta relevante en este asunto. Para Sergei Eisenstein, cineasta soviético de principios del siglo xx, el cine es fundamentalmente montaje de imágenes en búsqueda de un materialismo dialéctico visual; en este sentido, son reveladoras las teorías que sobre esta técnica elaboró el director de Acorazado Potemkin; cabe destacar su concepción del montaje como ideograma y la teoría del montaje de atracciones: en primer lugar, la yuxtaposición secuencial de imágenes cinematográficas propias del montaje producen un efecto perceptivo e intelectivo de escritura de ideogramas; en japonés, éstos últimos se forman mediante la combinación de dos o más jeroglíficos sencillos que corresponden a objetos, pero, que en el ideograma final producto de los jeroglíficos, se representa un concepto y no una suma de objetos; esta idea se aplica al cine, en el que la combinación secuenciada de dos imágenes de objetos producen un concepto: por ejemplo "un cuchillo + un corazón = 'dolor'”' $;$; en segundo lugar tenemos a las imágenes intermedias indirectas o atracciones, aparentemente desconectadas de las acciones

\footnotetext{
${ }^{4}$ Bürger, Peter: Teoría de la Vanguardia, Península, Barcelona, 2000. "En las obras de arte orgánicas (simbólicas) la unidad de lo general y lo particular se da sin mediaciones; en las obras inorgánicas (alegóricas), por el contrario, entre las que se encuentran las obra de vanguardia, hay mediación. Aquí el momento de la unidad está en cierto modo contenido muy ampliamente, y en el caso extremo sólo lo produce el receptor", p. 112.

${ }^{5}$ Ibíd., p. 142.

${ }^{6}$ Eisenstein, Sergei: Teoría y técnicas cinematográficas, Rialp, Madrid, 2002, p. 85.
} 
precedente y posterior, pero que establecen un puente y crean una atmósfera entre ellas, continuando por medio de la interrupción la acción precedente en la posterior?

Cine Sólido hace referencia a estos dos tipos de montaje: al de la obra de arte vanguardista al utilizar fragmentos de realidad (objetos) sobre un espacio real, que, por tiempo limitado, se convierte en plano de representación, en el que los objetos tienen el carácter ambivalente tanto como estado de cosas actual como de signos virtuales de lectura artística; y al de la obra cinematográfica eisensteniana, produciendo ideogramas o conceptos a partir de la combinación de objetos, y, como conjunto total de objetos que describen la secuencia, una imagen atracción, que conecta los espacios reales de donde proceden cada uno de los objetos con el espacio de exposición o montaje propiamente dicho, en una superposición o sobreimpresión fotográfica entre el espacio actual y los espacios virtuales a los que los objetos individualmente convocan. En el sentido que le atribuye Walter Benjamin, la instalación artística Cine Sólido se comporta como una imagen dialéctica ${ }^{8}$, un instante de suspensión del transcurrir del tiempo, en el que el pasado y el presente, el allí y el aquí, se conectan formando tensiones dialécticas; en algunas cosas esta imagen dialéctica recuerda al concepto de imagen-tiempo que expondremos a continuación.

\section{IMAGEN-TIEMPO}

¿Qué es una imagen-tiempo para Gilles Deleuze? Es un tipo de imagen característica del cine moderno - desde el neorrealismo italiano al cine experimental de las neovanguardias - cuya principal cualidad es la activación del pensamiento en el espectador por encima de otras activaciones motoras, afectivas o sensoriales, propias de las imágenes-movimiento que conforman el cine clásico ${ }^{9}$. El tiempo, en el tipo de imágenes cinematográficas modernas (imagen-tiempo), se presenta de forma directa, dando lugar a "situaciones ópticas y sonoras puras" que, al desconectar a las cosas de sus "nexos sensoriomotores", hace que entre todas ellas se establezcan relaciones que conforman a la imagen-tiempo como legible y no sólo como visible; los movimientos de cámara en este tipo de imágenes funcionan como una conciencia que "establece relaciones mentales" entre las diferentes partes de la imagen, haciéndose manifiesto el proceso de pensamiento.

Uno de los estados que conforman a la imagen-tiempo es la imagen-cristal; ésta es un tipo de imagen fruto del intento del cine moderno, no sólo de describir visualmente unos acontecimientos relacionados sino de dotar de todo un universo virtual "fuera de campo" a las imágenes que se muestran en las películas; las imágenes-cristal son el producto de ese circuito establecido entre la imagen actual y las "imágenes-recuerdo, imágenes-sueño, imágenes-mundo".

Llevando esta tendencia a su culminación diremos que la propia imagen actual tiene una imagen virtual que le corresponde como un doble o un reflejo. En términos bergsonianos, el objeto real se refleja en una imagen en espejo como imagen virtual que, por su lado y simultáneamente, envuelve o refleja a lo real: hay "coalescencia" entre ambos. Hay formación de una imagen de dos caras, actual y virtual. Es como si una imagen en espejo, una fotografía, una tarjeta postal cobraran vida, se independizaran y pasaran a lo actual, sin perjuicio de que la imagen actual vuelva en el espejo, recobre su sitio en la tarjeta postal o en la fotografía, según un doble movimiento de liberación y de captura. ${ }^{10}$

La imagen-cristal se asemeja al vidrio de dos caras de una ventana en las que hemos realizado unos dibujos o pinturas indistintamente y que se perciben simultáneamente, a pesar de formar parte de lo interno y lo externo; en el cine moderno, este cualidad cristalina se consigue mediante el uso de imágenes reflejadas en espejo o en superficies pulidas y brillantes, o con la inclusión de la imagen dentro de la imagen, o el cine dentro del cine; en todos estos casos se produce un circuito que hace que el personaje de la imagen actual se virtualice por la presencia de su imagen virtual en el espejo, y al mismo tiempo el reflejo se actualice en relación al personaje

\footnotetext{
${ }^{7}$ Deleuze, Gilles: La imagen-movimiento, Paidós, Barcelona, 1994.

“(...) una acción puede prolongarse en representaciones escultóricas y plásticas que nos alejan de la situación presente: por supuesto, los leones de piedra en Potemkin, pero sobre todo las series escultóricas de Octubre (por ejemplo, la llamada de los contrarrevolucionarios a la religión, se prolonga en una serie de fetiches africanos, divinidades hindúes y budas chinos). En Lo viejo y lo nuevo, este segundo aspecto cobra toda su importancia: la acción está suspendida, ¿funcionará la desnatadora? Cae una gota y después una oleada de leche, pero que va a prolongarse en imágenes de chorros de agua y chorros de fuego sustitutivos (un manantial de leche, una explosión de leche)", p. 255.

${ }^{8}$ Concepto que, por falta de espacio, no podemos tratar en esta comunicación. Las ideas de Walter Benjamin y Aby Warburg sobre las imágenes materialistas y la historia son el punto de partida para esta idea de IMAGEN DIALÉCTICA.

${ }^{9}$ Deleuze, Gilles: La imagen-tiempo, Paidós, Barcelona, 1987.

"La mirada imaginaria hace de lo real algo imaginario. Al mismo tiempo que se torna real a su vez y nos da de nuevo realidad. Es como un circuito que intercambia, corrige, selecciona, y nos vuelve a lanzar", p. 21.

"Un tópico es una imagen sensoriomotriz de la cosa. Como dice Bergson, no percibimos la cosa o la imagen entera, percibimos siempre menos que eso, sólo percibimos lo que estamos interesados en percibir, o, mejor dicho, lo que tenemos interés en percibir a causa de nuestros intereses económicos, de nuestras creencias ideológicas, de nuestras exigencias psicológicas. Así pues, de ordinario no percibimos más que tópicos. Pero si nuestros esquemas sensoriomotores se descomponen o se rompen, entonces puede aparecer otro tipo de imagen: una imagen óptica-sonora pura, la imagen entera y sin metáfora que hace surgir la cosa en sí misma, literalmente, en su exceso de horror o de belleza, en su carácter radical o injustificable, pues ya no tiene que ser «justificada», bien o mal...", pp. 35-36. ${ }^{10}$ lbíd., pp. 97-98.
} 
reflejado; parece que al mostrarse simultáneamente la imagen actual y la virtual, la cosa o personaje se nos aparezca completo, en toda su intensidad y dimensión.

¿Por qué Cine Sólido puede considerarse una imagen-tiempo, en su formato de imagen-cristal? Al percibir un conjunto heterogéneo de objetos domésticos o de uso habitual estéticamente ordenados sobre el suelo de una sala surgen dos tipos de inquietudes, una retrospectiva y otra prospectiva. ¿Qué ha pasado aquí? Alguien ha realizado un gasto de energías al coleccionar unos objetos banales aparentemente sin conexiones conceptuales y mostrarlos sobre el suelo, fuera de sus lugares habituales de uso y almacenamiento; una sensación de extrañeza nos asalta debido a este comportamiento inusual. ¿Qué objetivo o finalidad tiene esta colección de objetos? La ordenación y espaciamiento de los objetos no parece azarosa o fruto de la casualidad, existe una economía simbólica de los objetos que, junto con el texto que titula el conjunto, incita a elaborar pensamientos, teorías, intuiciones, sobre la instalación de imágenes sólidas y texto, en esta especie de emblema estereométrico. El pasado y el futuro se funden en el instante presente del receptor de Cine Sólido, transformándose el momento en una porción completa de tiempo, compuesta simultáneamente de sus tres estados. El tiempo representado directamente.

Al encontrarnos con la instalación, no surge la necesidad de interactuar físicamente con los objetos, no nos asalta el deseo de usarlos ya que al hallarse descontextualizados pierden su habitual uso y función, los "nexos sensoriomotores" se inhiben en contraposición con la aparición de una "situación óptica pura": nos basta con observar los objetos, acercarnos, alejarnos o rodearlos mientras la mirada acciona los pensamientos, una mirada que se comporta como los movimientos de cámara de la conciencia; establecemos relaciones conceptuales entre los objetos en colaboración con el texto; Cine Sólido, por tanto, se torna legible por las posibles conexiones virtuales entre los objetos, en el intento de descubrir la lógica interna de la instalación. Esa legibilidad, esa sensación de que los útiles no responden a una función de uso (conocida por todos) sino que hay algo más detrás de esa combinación concreta, convoca ante nosotros a las imágenes virtuales, a las posibilidades simbólicas de los objetos que se funden con las imágenes actuales 0 tópicas que de ellos tenemos. Experimentar Cine Sólido no es sólo apreciar el estado de cosas actual, los objetos reconocidos, es además imaginar infinidad de estados de cosas virtuales a partir de las conexiones dialécticas que se establecen entre ellos, los objetos leídos y pensados.

\section{PARACINEMA}

De manera telegráfica me gustaría mencionar que lo cinematográfico no se encuentra únicamente en el cine convencional, compuesto por el dispositivo film-proyector-pantalla; el montaje, la relación dialéctica de imágenes, o la modulación del espacio y la luz producen efectos cinematográficos fuera de su medio específico; a esto se lo denomina paracinema ${ }^{11}$. Cine Sólido se inscribe en este concepto de paracinema porque produce efectos cinematográficos de otra manera; a fin de cuentas las películas se "realizan" siempre en nuestras cabezas.

Para aportar un poco más de luz en este asunto del paracinema es conveniente referirnos al trabajo realizado por el historiador del arte George Kubler que, entre otras ideas, califica a los objetos como "acciones fósiles"12, y relaciona directamente historiografía y cine, comparando los objetos con fotogramas de una película en movimiento; cada objeto concreto no sería más que una instantánea tomada de la duración del objeto-tipo, desde su origen hasta la última de las réplicas realizadas.

Movimiento es probablemente un nombre inapropiado para los cambios que ocurren entre los miembros tempranos y tardíos de una serie de réplicas. Empero, una serie de réplicas, cada una hecha en un tiempo diferente, y todas relacionadas como réplicas que se basan en la misma forma original, describen a través del tiempo una apariencia de movimiento como la de los cuadros de una película que registra instantes sucesivos de una acción, que produce la ilusión de movimiento conforme pasan rápidamente por el rayo lumínico. ${ }^{13}$

Cine Sólido, al trabajar con todo tipo de enseres cotidianos, establece conexiones entre "fotogramas" representantes de diferentes duraciones de objetos-tipo, de "acciones fósiles", con lo que el montaje dialéctico de artefactos presenta una modalidad de paracinema.

\footnotetext{
${ }^{11}$ Para conocer ampliamente el concepto de PARACINEMA recomiendo la lectura de dos textos de Collado, Esperanza: a) Paracinema. La desmaterialización del cine en las prácticas artísticas, Trama, Madrid, 2012; b) Paracinema. Del material fílmico a la desmaterialización del cine [tesis], Universidad de Castilla-La Mancha, 2008.

${ }^{12}$ Kubler, George: La Configuración del Tiempo, Alberto Corazón, Madrid, 1975, p. 71.

${ }^{13}$ Ibíd., p. 94.
} 


\section{CONCLUSIONES}

\section{LEER EL ESPACIO}

El uso prolongado de tecnologías transforma tanto a los individuos como a las sociedades; considero que Cine Sólido es una tecnología artística de lectura (y por lo tanto escritura) del espacio y que, en el desarrollo de su práctica habitual, forma actitudes mentales para la interpretación crítica del entorno, aquello que pretendía leer Benjamin en los escaparates de los pasajes parisinos en referencia a la modernidad, o en conseguir detectar las mediaciones espaciales que Olafur Eliasson ${ }^{14}$ atribuye a las instituciones, fuerzas invisibles que determinan nuestro comportamiento y forma de pensar. Cine Sólido ayudaría a superponer las capas virtuales de significaciones sobre la base actual de espacios y objetos meramente identificados y reconocidos, fomentando el pensamiento crítico sobre el ambiente.

\section{FUENTES REFERENCIALES.}

Barthes, Roland: S/Z, Siglo Veintiuno, Madrid, 1980.

Bürger, Peter: Teoría de la Vanguardia, Península, Barcelona, 2000.

Collado, Esperanza: Paracinema. La desmaterialización del cine en las prácticas artísticas, Trama, Madrid, 2012.

Paracinema. Del material filmico a la desmaterialización del cine [tesis], Universidad de Castilla-La Mancha, 2008.

Deleuze, Gilles: La imagen-movimiento, Paidós, Barcelona, 1994.

La imagen-tiempo, Paidós, Barcelona, 1987.

Eco, Umberto: Lector in fábula, Lumen, Barcelona, 1993.

Eisenstein, Sergei: Teoría y técnicas cinematográficas, Rialp, Madrid, 2002

Eliasson, Olafur: Leer es respirar, es devenir, Gustavo Gili, Barcelona, 2012.

Goodman, Nelson: Maneras de hacer mundos, Visor, Madrid, 1990.

Kubler, George: La Configuración del Tiempo, Alberto Corazón, Madrid, 1975.

${ }^{14}$ Eliasson, Olafur: Leer es respirar, es devenir, Gustavo Gili, Barcelona, 2012. 